\title{
Sepsis severity predicts outcome in community-acquired pneumococcal
} pneumonia

\author{
B. Schaaf*, J. Kruse*, J. Rupp ${ }^{\#}$, R.R. Reinert ${ }^{\dagger}$, D. Droemann ${ }^{+}$, P. Zabel ${ }^{+}$, \\ S. Ewig ${ }^{\S}$ and K. Dalhoff*
}

ABSTRACT: Easily performed prognostic rules are helpful for guiding the intensity of monitoring and treatment of patients. The aim of the present study was to compare the predictive value of the sepsis score and the Confusion, Respiratory rate ( $\geqslant 30$ breaths $\mathrm{min}^{-1}$ ), Blood pressure (systolic value $<90 \mathrm{mmHg}$ or diastolic value $\leqslant 60 \mathrm{mmHg}$ ) and age $\geqslant 65$ yrs (CRB-65) score in 105 patients with community-acquired pneumococcal pneumonia. In addition, the influence of timing of the antimicrobial treatment on outcome was investigated. The sepsis and the CRB-65 scores were used to allocate patients to subgroups with low, intermediate and high risk.

Comparable, highly predictive values for mortality were found for both scores (sepsis score versus CRB-65): 1) low-risk group, 0 versus $0 \%$; 2) intermediate-risk group, 0 versus $8.6 \%$; 3) highrisk group, 30.6 versus $40 \%$, with an area under the curve of 0.867 versus 0.845 . Patients with ambulatory antibiotic pre-treatment had less severe disease with a lower acute physiology score, lower white blood cell count and a faster decline of C-reactive protein levels. No pre-treated patient died.

In summary, both scores performed equally well in predicting mortality. The prediction of survival in the intermediate-risk group might be more accurate with the sepsis score. Pre-hospital antibiotic treatment was associated with less severe disease.

KEYWORDS: Antibiotic treatment, pneumococcal infection, pneumonia, risk classification, sepsis

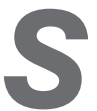

treptococcus pneumoniae remains the most frequent pathogen in adults with community-acquired pneumonia (CAP) and a leading cause of community-acquired sepsis [1]. Case fatality rates are high despite the availability of highly active antimicrobial agents, especially in the elderly and patients with risk factors [2]. The emergence of drug-resistant S. pneumoniae (DRSP) may further hamper the efficacy of treatment, at least with some groups of anti-infectives [3].

An easily performed prognostic procedure which may more accurately predict outcome of patients at admission may be helpful for guiding the intensity of monitoring and treatment. In the past, multiple prognostic factors, including age, comorbidities, low body temperature and leukopenia [4], and more complex severity scores, such as the Acute Physiology and Chronic Health Evaluation II score, were described to be predictive for survival [5]. Alternatively, pneumonia severity scores, such as the pneumonia severity index [6] or the recently developed Confusion, Urea $\left(>7 \mathrm{mmol} \cdot \mathrm{L}^{-1}\right)$, Respiratory rate $\left(\geqslant 30 \mathrm{breaths} \cdot \mathrm{min}^{-1}\right)$, Blood pressure (systolic value $<90 \mathrm{mmHg}$ or diastolic value $\leqslant 60 \mathrm{mmHg}$; CURB) and age $\geqslant 65$ yrs (CURB-65), and Confusion, Respiratory rate $\left(\geqslant 30\right.$ breaths $\left.\cdot \mathrm{min}^{-1}\right)$, Blood pressure (systolic value $<90 \mathrm{mmHg}$ or diastolic value $\leqslant 60 \mathrm{mmHg}$ ) and age $\geqslant 65$ yrs (CRB-65) scores [7], are applied in CAP. However, in a recent analysis of the Patient Outcomes and Research Team study, $>50 \%$ of hospitalised CAP patients developed severe sepsis during the course of the disease [8], indicating that systemic infection is frequent. Therefore, to date it is unclear whether a pneumonia severity score or a sepsis score, according to the definition of BONE et al. [9], focusing on the systemic signs and sequelae of infection has the highest potential to predict outcome.

In addition to host factors, which are measured according to the aforementioned scores, treatmentrelated factors may influence the outcome. The
AFFILIATIONS

*Medical Clinic III, and

\#Institute of Microbiology, University of Lübeck, Lübeck,

"Institute of Microbiology, National Reference Centre for Streptococci, University Hospital (RWTH), Aachen ${ }^{+}$Medical Clinic, Research Centre Borstel, Borstel, and

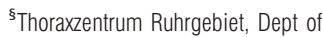
Respiratory Medicine and Infectious Diseases, Bochum, Germany.

CORRESPONDENCE

B. Schaaf

Medical Clinic III

University of Lübeck

Ratzeburger Allee 160

D-23538 Lübeck

Germany

Fax: 494515006014

E-mail: schaaf@uni-luebeck.de

Received:

February 202007

Accepted after revision:

May 142007

STATEMENT OF INTEREST

None declared.

European Respiratory Journal Print ISSN 0903-1936 Online ISSN 1399-3003 
time between admission and the first antibiotic dose and combination therapy in severe CAP were reported to be associated with a favourable outcome [10], but this finding has not been confirmed in other studies [11]. A possible explanation is that the major part of treatment delay may occur in the ambulatory setting, where timely diagnosis and treatment pose even greater problems. The impact of pre-hospital treatment on the outcome of pneumococcal disease in hospitalised patients has not yet been evaluated.

Therefore, the aim of the present study was to answer the following questions. 1) Is the sepsis score able to predict mortality of patients with pneumococcal pneumonia as accurately as the CRB-65 CAP score? 2) Does the timing of antibiotic treatment influence the outcome of this patient population?

\section{METHODS}

\section{Case definition}

A case of community-acquired pneumococcal pneumonia was defined as a diagnosis of CAP in combination with the isolation of S. pneumoniae from blood, the cerebrospinal fluid, other sterile sites or respiratory secretions of high quality, i.e. $\geqslant 10^{4}$ colony forming units $\cdot \mathrm{mL}^{-1}$ of $S$. pneumoniae in bronchoalveolar lavage (BAL), and purulent sputum or tracheal secretions (only samples with $>25$ polymorphonucleates and $<10$ squamous cells/high-power field). In addition, cases with positive urinary antigen test were included if the clinical diagnosis was CAP. The diagnosis of pneumonia was based on clinical symptoms (fever, respiratory symptoms, typical auscultatory findings), new or progressive infiltrate on chest radiography and laboratory signs of infection.

\section{Patients}

From December 1998 until November 2004, 105 adult patients hospitalised with community-acquired pneumococcal pneumonia at the University Hospital Lübeck (Lübeck, Germany) and two community hospitals from the same region (Medical Clinic, Sana Hospital, Schleswig-Holstein and Medical Clinic, Asklepios Hospital, Bad Oldesloe, Germany) were investigated in a prospective manner. Patients with defined immunodeficiencies (haematological or solid neoplasia, glucocorticoid or cytotoxic therapy, HIV infection or immunoglobulin deficiency) were excluded from the study.

Data on the influence of genetic polymorphisms on the clinical course of the disease have been described previously [12, 13]. The study was approved by the institutional ethics committee. Written informed consent was obtained from patients or their relatives.

\section{Laboratory and clinical data}

Demographic data, comorbidities, complications and previous antibiotic therapy were prospectively assessed. A total of 70 (66.7\%) out of the 105 pneumococcal isolates were available for serotyping. The clinical status, including the sepsis severity and the acute physiology score (APS), was documented at days 1, 2 and 7. Assessment of the in-hospital mortality included early and late death defined as death during the first week (days 1-7) and death during the second week or later ( $\geqslant$ day 8), respectively.

\section{Antibiotic susceptibility testing}

The antibiotic resistance of $S$. pneumoniae strains was determined according to the standards and guidelines from the Clinical and Laboratory Standards Institute (CLSI) [14]. Briefly, direct colony suspensions, equivalent to a $0.5 \mathrm{McF}$ arland standard, were inoculated on Mueller-Hinton agar with 5\% sheep blood and incubated at $35^{\circ} \mathrm{C}$ in a $5 \% \mathrm{CO}_{2}$ atmosphere for $24 \mathrm{~h}$. The panel of routinely tested antibiotics included penicillin G, clindamycin, erythromycin A, vancomycin, ceftriaxone and doxycycline. Resistance testing for fluoroquinolones was not routinely performed, since resistance rates of respiratory fluoroquinolones in the present authors' region are $<1 \%[15,16]$. S. pneumoniae ATCC 49619 was used as a control strain. Current CLSI interpretive criteria were used to define antimicrobial resistance.

\section{Serotyping}

Pneumococcal isolates were serotyped by Neufeld's Quellung reaction using type and factor sera provided by the Statens Serum Institut, Copenhagen, Denmark.

\section{Sepsis score and CRB-65 score}

The sepsis score (nonsepsis, sepsis, severe sepsis and septic shock) was made according to the definition provided by the American College of Chest Physicians/Society of Critical Care Medicine Consensus Conference 1992, adapted by BONE et al. [9]. In brief, sepsis was defined as two or more of the following criteria in combination with pneumococcal infection: 1) temperature $>38^{\circ} \mathrm{C}$ or $<36^{\circ} \mathrm{C}$; 2) cardiac frequency $>90$ beats $\cdot \mathrm{min}^{-1}$; 3) respiratory frequency $>20$ breaths $\cdot \mathrm{min}^{-1}$ or carbon dioxide tension $<32 \mathrm{mmHg}$; and 4) white blood cell (WBC) count $>12,000$ cells $\cdot \mathrm{mm}^{-3}$ or $<4,000$ cells $\cdot \mathrm{mm}^{-3}$ or $>10 \%$ band forms. Severe sepsis was defined as sepsis associated with organ dysfunction together with perfusion abnormalities. One of the following criteria had to be met: 1) $\mathrm{pH}<7.3$; 2) pneumonia-associated confusion; 3) acute renal failure; 4) disseminated intravasal coagulopathy; 5) systolic blood pressure <90 mmHg; and/or 6) an arterial oxygen tension/inspiratory oxygen fraction ratio $<200$. Septic shock was defined as sepsis associated with sepsis-induced hypotension despite adequate fluid resuscitation.

The CRB-65 score was calculated as described by LiM et al. [7], with one point for each of Confusion, Respiratory rate $\geqslant 30$ breaths $\cdot \mathrm{min}^{-1}$, low systolic $(<90 \mathrm{mmHg})$ or diastolic $(\leqslant 60 \mathrm{mmHg})$ Blood pressure and age $\geqslant 65 \mathrm{yrs}$.

In line with previous studies [17], the sepsis and the CRB-65 scores were divided into low-, intermediate- and high-risk classes as follows. Sepsis severity score: 1) low-risk class, nonsepsis; 2) intermediate-risk class, sepsis; and 3) high-risk class, severe sepsis or septic shock. CRB-65 score (five-point scale): 1) low-risk class $=0$; 2) intermediate-risk class $=1$ or 2 ; and 3) high-risk class $=3$ or 4 .

\section{Influence of antimicrobial treatment on outcome}

In order to assess the impact of treatment-related factors, the present authors studied the influence of pre-hospital antimicrobial treatment and in-hospital antimicrobial treatment on clinical course, parameters of inflammation and patient outcome. 
Inappropriate treatment was defined as discordant treatment (isolation of pneumococci with resistance against the drug used) or treatment with drugs not recommended for the treatment of pneumococcal pneumonia in current guidelines (e.g. ciprofloxacin).

\section{Statistical analysis}

Patients were grouped into low-, intermediate- and high-risk classes according to the results of the sepsis score and the CRB65 score [17]. The Cochrane Armitage Test was used for trend of category variables. Fisher's exact test (two-tailed) was used for association of discontinuous variables with mortality. Continuous variables were compared by the Mann-Whitney U-test (values are provided as mean \pm SEM). A p-value $<0.05$ was considered statistically significant.

\section{RESULTS}

\section{Demographic data, risk factors and comorbidities}

Demographic data, risk factors and comorbidities are presented in table 1. Most patients had at least one risk factor or comorbidity. The total in-hospital mortality was $10.5 \%$.

Diagnosis of pneumococcal infection was made by recovery of S. pneumoniae from blood $(n=64)$, cerebrospinal fluid $(n=2)$, BAL $(n=11)$, sputum or tracheal secretions $(n=16)$, pleural fluid $(\mathrm{n}=4)$, BAL and blood $(\mathrm{n}=2)$, cerebrospinal fluid and blood $(n=1)$ and by urinary antigen test $(n=5)$.

\section{Pneumococcal serotypes}

Serotyping data were available in 70 patients and were comparable to recent data from Germany [18]. The leading serotypes were $3(18.6 \%), 14(17.1 \%)$ and $7 \mathrm{~F}(10 \%)$. The data were as follows: serotype $1(n=3) ; 3(n=13) ; 4(n=6) ; 5(n=1)$; $6 \mathrm{~B}(\mathrm{n}=2) ; 7 \mathrm{~F}(\mathrm{n}=7) ; 8(\mathrm{n}=4) ; 9 \mathrm{~A}(\mathrm{n}=3) ; 9 \mathrm{~L}(\mathrm{n}=1) ; 9 \mathrm{~V}(\mathrm{n}=2) ; 10 \mathrm{~A}$ $(\mathrm{n}=1) ; 12 \mathrm{~F}(\mathrm{n}=4) ; 14(\mathrm{n}=12) ; 17 \mathrm{~F}(\mathrm{n}=1) ; 19 \mathrm{~F}(\mathrm{n}=1) ; 19 \mathrm{C}(\mathrm{n}=1)$; $23 \mathrm{~A}(\mathrm{n}=2) ; 23 \mathrm{~F}(\mathrm{n}=2) ; 33 \mathrm{~F}(\mathrm{n}=2)$; and $38(\mathrm{n}=1)$. According to this data, $90 \%$ of the serotyped bacteria would have been covered by the 23 valent pneumococcal polysaccharide

\begin{tabular}{lc} 
TABLE 1 & $\begin{array}{c}\text { Demographic factors, comorbidities and risk } \\
\text { factors in patients with community-acquired } \\
\text { pneumococcal pneumonia }\end{array}$ \\
Subjects $\mathbf{n}$ & 105 \\
Age yrs & $64.9(24-96)$ \\
Sex male & 57.2 \\
Risk factors $\geqslant \mathbf{1}$ & 84.8 \\
Age $\geqslant 5$ yrs & 54.3 \\
Smokers & 43.8 \\
Alcohol abuse & 17.1 \\
Comorbidities $\geqslant \mathbf{1}$ & 61.9 \\
Chronic lung disease & 36.2 \\
Chronic heart disease & 30.5 \\
Diabetes mellitus & 20.0 \\
Chronic liver failure & 1.9 \\
Chronic renal failure & 19.0 \\
Risk factor or comorbidity $\geqslant \mathbf{1}$ & 89.5 \\
\hline & \\
Data are presented as mean (range) or \%, unless otherwise stated. & \\
&
\end{tabular}

vaccine. The serotypes were equally distributed over all risk classes (data not shown).

\section{Disease severity}

Single variables (temperature, C-reactive proteins (CRP) levels, leukocytes, age, bacteraemia and comorbidities) were not associated with mortality (data not shown).

The predictive values of the sepsis and the CRB-65 scores were excellent (figs 1 and 2). The sepsis score at day 1 was significantly related to mortality (table 2). At admission, 36 $(34.3 \%)$ patients were in the high-risk class (severe sepsis or septic shock) with a mortality of $30.5 \%$, compared with 45 $(42.9 \%)$ patients in the intermediate-risk class with a mortality of $0 \%$, and $24(22.9 \%)$ patients in the low-risk class with a mortality of $0 \%(\mathrm{p}<0.0001)$.

The CRB-65 score was also predictive for mortality: 16 patients in the high-risk class had a mortality rate of $40.0 \%$; 58 patients in the intermediate-risk class had a mortality rate of $8.6 \%$; and 32 patients in the low-risk class had a mortality rate of $0 \%$ (table 2).

Taking into consideration the different risk classes, there is a trend for a better prediction of survival in the intermediate-risk class as defined by the sepsis score; survival in this subgroup was 100\% (95\% confidence interval: 92.1-100.0) compared with $91.4 \%$ (81.0-97.1) with the CRB-65 score ( $\mathrm{p}=$ nonsignificant).

\section{Early versus late death}

All patients were observed until discharge. Death occurred after a mean period of $12.5 \pm 13.7$ (1-40) days. The length of hospital stay in survivors was $19.1 \pm 10.8$ (5-53) days.

Early death during the first week was seen in six patients $(2.7 \pm 1.9(1-5)$ days $)$ and was attributable to uncontrolled septic shock $(n=2)$, acute respiratory failure (acute respiratory distress syndrome; $n=2)$ and meningitis $(n=2)$. Late death was seen in five patients (19.1 \pm 10.8 (9-40) days; fig. 3). Late death was observed after a transient recovery from sepsis in all patients and was attributable to secondary organ failure,

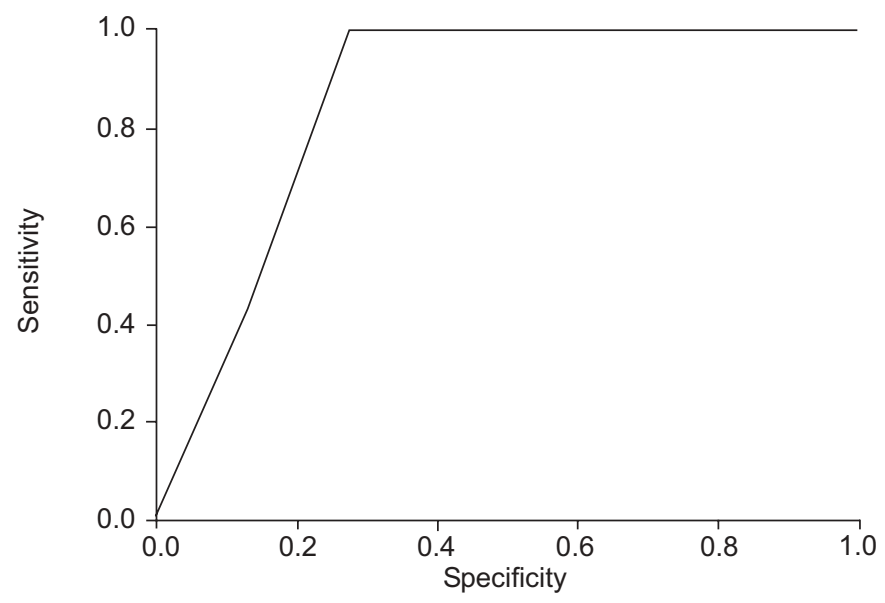

FIGURE 1. Receiver operating characteristic curve of predicting mortality with the sepsis score for patients with community-acquired pneumococcal pneumonia. Area under the curve $=0.867$ : SEM $=0.038: 95 \%$ confidence interval: $0.796-0.938$ 


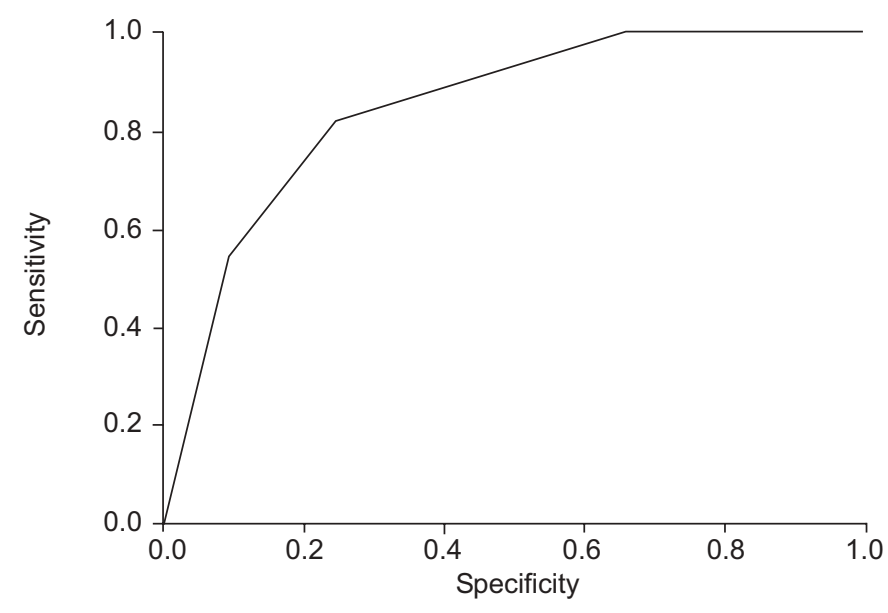

FIGURE 2. Receiver operating characteristic curve of predicting mortality with the Confusion, Respiratory rate ( $\geqslant 30$ breaths $\cdot \mathrm{min}^{-1}$ ), Blood pressure (systolic value $<90 \mathrm{mmHg}$ or diastolic value $\leqslant 60 \mathrm{mmHg}$ ) and age $\geqslant 65$ yrs score for patients with community-acquired pneumococcal pneumonia. Area under the curve $=0.845$; SEM $=0.054 ; 95 \%$ confidence interval $=0.739-0.951$.

including secondary bacterial pneumonia with respiratory failure $(n=3)$, hypoxic cerebral failure after meningitis $(n=1)$ and ischemic cerebral insult $(n=1)$.

At admission, late death patients were less severely ill than early death patients. Late death was associated with a lower APS at admission $(11 \pm 2.45$ versus $16.33 \pm 4.6$ for late and early death, respectively; $\mathrm{p}=0.03)$.

In addition, the performance of the two scores in predicting early or late death was compared. Using the sepsis score, all late-death patients were classified as high-risk patients at admission. In contrast, three out of five late-death patients were initially grouped in the intermediate-risk class using the CRB-65 score (table 2, fig. 3).

\section{Influence of DRSP on outcome}

Of the 100 patients in whom data on susceptibility testing were available, $10(10 \%)$ had DRSP isolated, erythromycin $(n=9)$ and intermediate penicillin resistance (minimum inhibitory concentration $0.12-1 \mu \mathrm{g} \cdot \mathrm{mL}^{-1} ; \mathrm{n}=1$ ). There was a trend towards less severe disease in patients with DRSP (mortality 0 versus $12.1 \%, p=0.1$; APS at admission $4.9 \pm 3.3$ versus $8.7 \pm 5.3$, $\mathrm{p}=0.03$; table 3 ).

\section{Influence of antimicrobial treatment on outcome}

Pre-hospital treatment

Thirteen patients $(12.4 \%)$ were treated with oral monotherapy before hospitalisation: ciprofloxacin $(n=4)$; levofloxacin $(n=1)$; macrolides $(n=3)$; cephalosporines $(n=3)$; penicillin $(n=1)$; and amoxicillin and/or clavulanic acid $(n=1)$.

In spite of the fact that $38.5 \%$ of these treatments were inappropriate (ciprofloxacin, $\mathrm{n}=4$ ) or discordant (macrolide resistance, $n=1$ ), patients with pre-hospital antibiotic treatment had less severe disease (table 4), as evidenced by lower APS values at admission $(p=0.02)$. In addition, lower WBC counts at admission $(p=0.002)$ and faster decline of CRP levels with lower values at day 7 were seen $(p=0.03)$ in pre-treated patients. A smaller proportion presented in the high-risk group (CRB-65 and sepsis score at admission) and none of the patients died ( 0 versus $12.0 \%$; $\mathrm{p}=$ nonsignificant).

Data are presented as mean $\pm S E M$, unless otherwise stated. CRP: C-reactive protein; APS: acute physiology score; CRB-65: Confusion, Respiratory rate $\left(\geqslant 30\right.$ breaths $\left.\cdot \mathrm{min}^{-1}\right)$, Blood pressure (systolic value $<90 \mathrm{mmHg}$ or diastolic value $\leqslant 60 \mathrm{mmHg}$ ) and age $\geqslant 65$ yrs.

In-hospital treatment

A delay of antibiotic therapy $>8 \mathrm{~h}$ after hospital admission was associated with a trend for better survival: 1) delay $>8 \mathrm{~h}$, mortality $0(0 \%)$ out of 16 ; and 2) delay $<8 \mathrm{~h}$, mortality 11 $(15.9 \%)$ out of $69(\mathrm{p}=0.1$; table 5$)$.

Mortality including early and late death according to risk class in the sepsis score and the Confusion, Respiratory rate $\left(\geqslant 30\right.$ breaths $\left.\cdot \mathrm{min}^{-1}\right)$, Blood pressure (systolic value $<90 \mathrm{mmHg}$ or diastolic value $\leqslant 60 \mathrm{mmHg}$ ) and age $\geqslant 65 \mathrm{yrs}$ (CRB-65) score ${ }^{\#}$

\begin{tabular}{|c|c|c|c|c|c|}
\hline & Alive & Dead & OR $(95 \% \mathrm{Cl})$ & Early death & Late death \\
\hline \multicolumn{6}{|l|}{ Sepsis score severity } \\
\hline Intermediate (sepsis) & $45(100)$ & $0(0)$ & $6.580(1.91-35.86)$ & 0 & 0 \\
\hline High (severe sepsis or septic shock) & $25(69.4)$ & $11(30.6)$ & $43.3(3.66-128.6)$ & 6 & 5 \\
\hline p-value & & & $<0.0001$ & & \\
\hline Intermediate (score 1 or 2) & $53(91.4)$ & $5(8.6)$ & $8.48(2.34-38.25)$ & 2 & 3 \\
\hline High (score 3 or 4 ) & $9(60.0)$ & $6(40.0)$ & $71.83(5.49-146.32)$ & 4 & 2 \\
\hline p-value & & & $<0.0001$ & & \\
\hline
\end{tabular}

Data are presented as $\mathrm{n}(\%)$, unless otherwise stated. OR: odds ratio; Cl: confidence interval. The sepsis score can be defined with regard to the risk class as follows: 1) low-risk class, nonsepsis; 2) intermediate-risk class, sepsis; 3) high-risk class, severe sepsis or septic shock. The CRB-65 score can be defined with regard to the risk class as follows: 1) low-risk class, 0 points; 2) intermediate-risk class, 1 or 2 points; 3) high-risk class, 3 or 4 points. ${ }^{\#}$ : Cochrane Armitage Trend Test for mortality. 


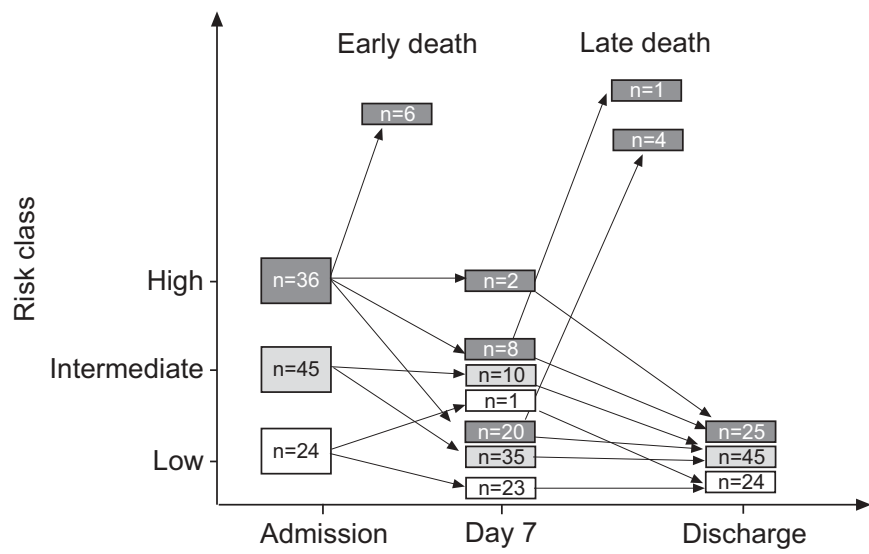

FIGURE 3. Course of the disease in patients with community-acquired pneumococcal pneumonia according to the risk class in the sepsis score at admission. $\square$ : low-risk class, nonsepsis; $\square$ : intermediate-risk class, sepsis; high-risk class, severe sepsis or septic shock.

Four out of 105 patients received inappropriate therapy with a drug not recommended for the treatment of pneumococcal pneumonia (mortality 9.9 versus $25 \%$ in patients with appropriate treatment, $\mathrm{p}=0.4)$. No patient received discordant treatment after admission.

Combination therapy was used in $52.4 \%$ of all patients (mostly a $\beta$-lactam with a macrolide or fluoroquinolone). No association of the use of combination therapy with outcome was seen (tables 6 and 7).

\section{DISCUSSION}

The main finding of the present study was that the sepsis score at admission has a high predictive value for the outcome of community-acquired pneumococcal pneumonia. Using the presence of severe sepsis and/or septic shock (high-risk class) as a cut-off, $30.5 \%$ of these patients died compared with $0 \%$ of the patients in the intermediate- and low-risk categories. The CRB-65 score also showed an excellent overall performance but

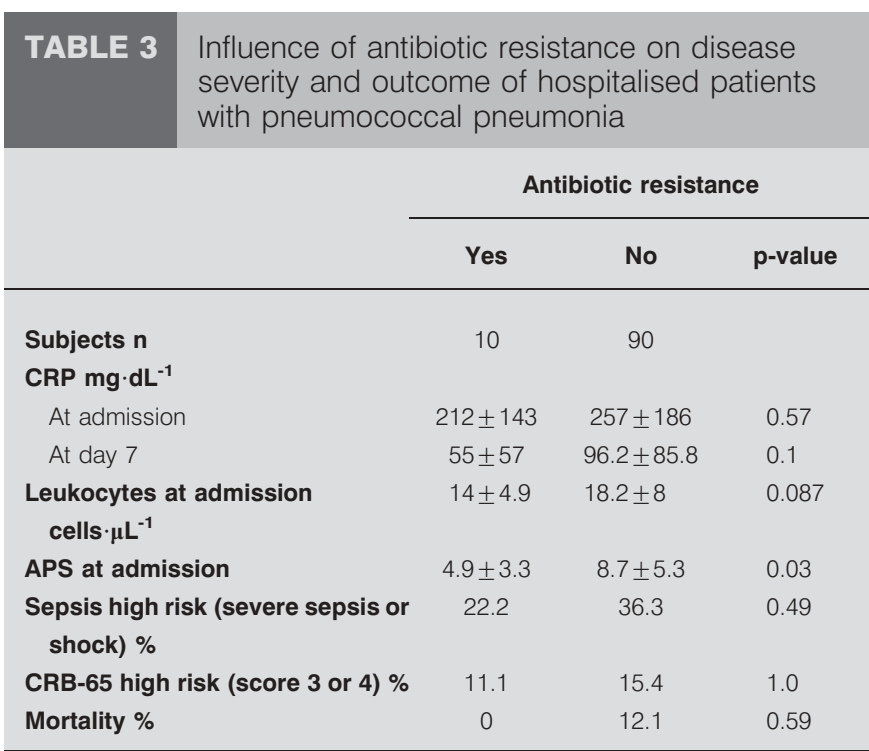

Data are presented as mean \pm SEM, unless otherwise stated. CRP: C-reactive protein; APS: acute physiology score; CRB-65: Confusion, Respiratory rate $\left(\geqslant 30\right.$ breaths $\cdot \mathrm{min}^{-1}$ ), Blood pressure (systolic value $<90 \mathrm{mmHg}$ or diastolic value $\leqslant 60 \mathrm{mmHg}$ ) and age $\geqslant 65 \mathrm{yrs}$. Five patients with urinary antigen were excluded.

appeared less discriminative, with a survival rate of $91.4 \%$ in the intermediate-risk class compared with $100 \%$ when using the sepsis score (table 2).

Furthermore, the current data show that pre-hospital antimicrobial treatment is associated with a favourable clinical course in patients with pneumococcal pneumonia in spite of the fact that $38.5 \%$ of ambulatory treatment courses were inappropriate or discordant (table 4).

For CAP, including pneumococcal infection, severity scores, such as the PSI and the CRB-65 score, are successfully used. The CRB-65 score performed equally well for predicting

\section{TABLE 4 Influence of pre-hospital treatment on disease severity and the outcome of hospitalised patients with pneumococcal pneumonia}

\begin{tabular}{|c|c|c|c|}
\hline & \multicolumn{3}{|c|}{ Pre-hospital antibiotic therapy } \\
\hline & Yes & No & p-value \\
\hline Subjects n & 13 & 92 & \\
\hline \multicolumn{4}{|l|}{ CRP $\mathrm{mg} \cdot \mathrm{dL}^{-1}$} \\
\hline At admission & $185 \pm 181$ & $263 \pm 178$ & 0.1 \\
\hline APS at admission & $5.2 \pm 4.1$ & $8.6 \pm 5.2$ & 0.02 \\
\hline Sepsis high risk \% (severe sepsis or shock) & 23.0 & 35.9 & 0.53 \\
\hline CRB-65 high risk \% (score 3 or 4 ) & 7.7 & 15.2 & 0.70 \\
\hline Mortality \% & 0 & 12.0 & 0.35 \\
\hline
\end{tabular}

Data are presented as mean \pm SEM, unless otherwise stated. CRP: C-reactive protein; APS: acute physiology score; CRB-65: Confusion, Respiratory rate ( $\geqslant 30$ breaths $\cdot \mathrm{min}^{-1}$ ), Blood pressure (systolic value $<90 \mathrm{mmHg}$ or diastolic value $\leqslant 60 \mathrm{mmHg}$ ) and age $\geqslant 65 \mathrm{yrs}$. 


\begin{tabular}{|c|c|c|c|c|}
\hline \multirow[t]{3}{*}{ TABLE 5} & \multicolumn{4}{|c|}{$\begin{array}{l}\text { Influence of the timing of in-hospital treatment on } \\
\text { disease severity and outcome of hospitalised } \\
\text { patients with pneumococcal pneumonia }\end{array}$} \\
\hline & & \multicolumn{3}{|c|}{ Delay of antibiotic therapy } \\
\hline & & $<8 \mathrm{~h}$ & $\geqslant 8 \mathrm{~h}$ & p-value \\
\hline Subjects $n$ & & 69 & 16 & \\
\hline \multicolumn{5}{|l|}{ CRP $\mathrm{mg} \cdot \mathrm{dL}^{-1}$} \\
\hline At admissior & & $286 \pm 179$ & $210 \pm 156$ & 0.1 \\
\hline At day 7 & & $98.8 \pm 82.0$ & $106.7 \pm 102.3$ & 0.84 \\
\hline \multicolumn{2}{|c|}{ Leukocytes at admission cells $\mu \mathrm{L}^{-1}$} & $18.4 \pm 7.7$ & $20.9 \pm 7.6$ & 0.18 \\
\hline \multicolumn{2}{|c|}{ APS at admission } & $9 \pm 5.2$ & $7.6 \pm 5$ & 0.41 \\
\hline \multicolumn{2}{|c|}{$\begin{array}{l}\text { Sepsis high risk \% (severe sepsis } \\
\text { or shock) }\end{array}$} & 40.6 & 25 & 0.4 \\
\hline \multicolumn{2}{|c|}{ CRB-65 high risk \% (score 3 or 4 ) } & 14.5 & 18.8 & 0.7 \\
\hline \multicolumn{2}{|c|}{ Mortality \% } & 15.9 & 0 & 0.1 \\
\hline
\end{tabular}

Data are presented as mean \pm SEM, unless otherwise stated. CRP: C-reactive protein; APS: acute physiology score; CRB-65: Confusion, Respiratory rate $\left(\geqslant 30\right.$ breaths $\cdot \mathrm{min}^{-1}$ ), Blood pressure (systolic value $<90 \mathrm{mmHg}$ or diastolic value $\leqslant 60 \mathrm{mmHg}$ ) and age $\geqslant 65 \mathrm{yrs}$. Patients with pre-hospital treatment were excluded. Data for timing of antibiotic treatment is missing in six patients.

outcome as the CURB and CURB-65 scores [19]. An association between the CURB-65 score and mortality in patients with bacteraemic pneumococcal pneumonia was recently demonstrated [20]. Conditions such as pneumococcal infection carry a high risk of systemic dissemination and septic shock. Even in CAP due to different aetiologies, the frequency of severe sepsis may exceed $50 \%$ [8]. Septic shock is a known risk factor for mortality from pneumococcal infection [21]. Therefore, scoring the severity of sepsis may add prognostic information in these patients. To the present authors' knowledge, the current study is the first that demonstrates a high predictive value of the sepsis score in patients with pneumococcal pneumonia. The current data are in line with a study by EwIG et al. [17] who found a high predictive value of the sepsis score in hospitalised CAP patients (mortality $1 \%$ in low- or intermediate-risk class). In addition, the authors observed an increased mortality rate of $8 \%$ in the intermediate-risk class by using the CURB score [17]. The predictive value of the CURB score has been evaluated in several studies. Recently, SPINDLER et al. [20] demonstrated an increasing mortality risk in patients with bacteraemic pneumococcal pneumonia according to the CURB-65 score. In that study [20], patients with intermediate risk had a high mortality rate of $15-20 \%$. For clinical pathways, an intermediate-risk class with increased mortality may be useful for the decision of hospital admission, but is less useful for hospital management. The sepsis score with its more discriminative prediction of mortality (low- and intermediateversus high-risk class) may be helpful to decide which patients need more intensive monitoring in the hospital (e.g. intensive care unit). A possible disadvantage of the sepsis severity score compared with the CRB-65 lies in the need of some additional laboratory and clinical investigations. However, these data should be known by the clinician caring for hospitalised CAP patients (e.g. septic encephalopathy, septic shock, respiratory

\begin{tabular}{|c|c|c|c|c|}
\hline \multirow[t]{2}{*}{ TABLE 6} & \multicolumn{4}{|c|}{$\begin{array}{l}\text { Antibiotic therapy used in } 105 \text { patients with } \\
\text { pneumococcal pneumonia }\end{array}$} \\
\hline & therapy $\#$ & $\mathbf{n}$ & No combination therapy & $\mathrm{n}$ \\
\hline \multirow{2}{*}{\multicolumn{2}{|c|}{$\begin{array}{l}\beta \text {-Lactam and macrolide } \\
\beta \text {-Lactam and aminoglyco- } \\
\text { side }\end{array}$}} & 48 & $\beta$-Lactam & 40 \\
\hline & & 6 & $\beta$-Lactam and nitroimidazol & 4 \\
\hline \multirow{2}{*}{\multicolumn{2}{|c|}{$\begin{array}{l}\beta \text {-Lactam and fluoroquino- } \\
\text { lone }\end{array}$}} & 1 & Fluoroquinolone & 5 \\
\hline & & & Lincosamide & 1 \\
\hline
\end{tabular}

insufficiency, acute renal failure, disseminated intravascular coagulopathy, low blood pressure or acidosis).

It has been previously observed [4] that $\sim 50 \%$ of the deaths in CAP patients are observed during the first 7 days due to direct septic complications, and the remaining $50 \%$ of the deaths are seen later. This observation can be confirmed for pneumococcal disease: $55 \%$ of the patients died during the first week and $45 \%$ of the deaths occurred later, after transient recovery due to secondary organ failure (fig. 3). Patients with early death had initially more severe disease with a higher APS. Interestingly, the weaker discriminative power of the CRB-65 score was more evident in patients with late death. The majority of these patients were initially grouped in the intermediate-risk class with the CRB-65 score, whereas the sepsis score correctly predicted the high risk in all late-death patients (table 2).

\begin{tabular}{|c|c|c|c|c|}
\hline \multirow[t]{3}{*}{ TABLE 7} & \multicolumn{4}{|c|}{$\begin{array}{l}\text { Influence of in-hospital combination therapy on } \\
\text { disease severity and outcome of hospitalised } \\
\text { patients with pneumococcal pneumonia }\end{array}$} \\
\hline & & \multicolumn{3}{|c|}{ Combination therapy } \\
\hline & & Yes & No & $p$-value \\
\hline \multicolumn{5}{|l|}{ CRP $\mathrm{mg} \cdot \mathrm{dL}^{-1}$} \\
\hline At admissio & & $269 \pm 197$ & $237 \pm 172$ & 0.5 \\
\hline At day 7 & & $74.3 \pm 70.2$ & $100.6 \pm 84.6$ & 0.1 \\
\hline $\begin{array}{l}\text { Leukocytes a } \\
\text { cells } \cdot \mu \mathrm{L}^{-1}\end{array}$ & admission & $17.9 \pm 6.2$ & $16.8 \pm 8.9$ & 0.18 \\
\hline APS at admis & sion & $9 \pm 5.7$ & $7.1 \pm 4.4$ & 0.13 \\
\hline $\begin{array}{l}\text { Sepsis high } \\
\text { sepsis or s }\end{array}$ & $\begin{array}{l}\text { isk \% (severe } \\
\text { lock) }\end{array}$ & 43.6 & 24 & 0.04 \\
\hline $\begin{array}{l}\text { CRB-65 high } \\
\text { or } 4 \text { ) }\end{array}$ & risk \% (score 3 & 18.2 & 10 & 0.27 \\
\hline Mortality \% & & 14.5 & 6 & 0.2 \\
\hline
\end{tabular}


None of the patients with intermediate- or low-risk class of the sepsis score deteriorated to severe sepsis (high-risk class) during hospitalisation, confirming the stability of this scoring system (fig. 3). The fact that simple sepsis, or systemic inflammatory response syndrome, has a low predictive potential for the development of more severe disease has been described previously and has served as an argument against the specificity of the sepsis score [8]. In the present authors' opinion the associated high predictive value for survival in these risk groups makes the sepsis score an useful instrument for assessing the risk of patients with serious pulmonary infections.

Several risk factors for pneumococcal infection have been described. Although the present study was not designed to study the incidence of pneumococcal infection, in 90\% of cases at least one risk factor or one comorbidity was found (table 1). The influence of comorbidities on outcome is under debate [4]. In the present analysis, single risk factors and comorbidities were not associated with sepsis severity or mortality, but all patients who died had at least one risk factor or comorbidity.

As expected, pneumococcal serotype analysis did not show any clear association with the outcome. In Germany, vaccination with 23 valent polysaccharide vaccine is recommended for patients aged $>60$ yrs and for all patients with comorbidities [22]. A total of $94 \%$ of the recovered serotypes would have been covered by the vaccine. Thus, a considerable part of the invasive pneumococcal infections observed could have been avoided by the vaccination of risk groups.

In line with other German cohorts [18], a low incidence of pneumococcal resistance (macrolide resistance $9 \%$, intermediate penicillin resistance $1 \%$ ) was found. The role of bacterial resistance, especially in discordant treatment (e.g. receipt of an antimicrobial drug inactive against $S$. pneumoniae in vitro), is questionable [23]. In the present study, all patients with pneumococcal resistance received concordant in-hospital treatment (e.g. receipt of at least one antibiotic with in vitro activity against $S$. pneumoniae). A trend towards less severe disease was found in patients with isolation of drug-resistant pneumococci (table 3).

Hospitalisation despite prior ambulatory antimicrobial treatment was seen in $12.4 \%$ of the current cohort of patients. It was associated with antibiotic resistance in a minority of cases. Interestingly, the present authors found a less severe course of disease and no deaths in pre-treated patients, in spite of the fact that pneumococci were isolated in all cases at admission and $38.5 \%$ had been treated either with inappropriate drugs, e.g. ciprofloxacin, or with macrolides in case of resistance. Pretreated patients had lower CRP and leukocyte values, together with a lower APS (table 4). In addition, less patients were in the high-risk group of the sepsis score and none of the pretreated patients died. This suggests that pre-hospital antibiotic treatment, although suboptimal in many cases, had a beneficial effect on the course of the disease, possibly by modulating the inflammatory response. In line with the present data, RuIz et al. [24] demonstrated a protective effect of prior ambulatory antimicrobial treatment in patients with severe CAP. Thus, rapid empiric treatment seems to be of importance for the course of CAP.
In contrast, the present authors were not able to confirm an influence of treatment delay in hospital, the use of combination therapy or inappropriate treatment on outcome (tables 5-7). Of note, these data are observational and are open to multiple biases. For instance, critically ill patients may receive immediate attention at the emergency room, leading to faster initiation of treatment and to the institution of combination therapy. This could lead to underestimation of the effect of treatment intensity and speed. Indeed, patients receiving early therapy and combination therapy seemed to be more severely ill at admission (tables 5 and 7). Conversely, a treatment delay of a few hours in hospital may be less important for the course than a delay in the pre-hospital phase, which may comprise days [11]

In conclusion, the sepsis severity assessment and pneumonia scoring with Confusion, Respiratory rate $\left(\geqslant 30\right.$ breaths $\left.\cdot \mathrm{min}^{-1}\right)$, Blood pressure (systolic value $<90 \mathrm{mmHg}$ or diastolic value $\leqslant 60 \mathrm{mmHg}$ ) and age $\geqslant 65 \mathrm{yrs}$ showed overall comparable performance in predicting mortality. There was a trend for a more accurate discrimination with sepsis assessment in patients with intermediate risk which has to be confirmed in larger cohorts. In hospitalised patients with communityacquired pneumococcal pneumonia, both instruments may be complementary for evaluating disease severity. Regarding modifiable factors, pre-hospital antimicrobial treatment was associated with less severe disease. Controlled studies may be warranted to elucidate the role of earlier initiation of treatment in the pre-hospital setting.

\section{ACKNOWLEDGEMENTS}

The authors would like to acknowledge the clinical cooperation of T.H. Huetteroth and R. Thielecke (Medical Clinic, Sana Hospital, Lüebeck-Travemuende, Germany), G. Hintze (Medical Clinic, Asklepios Hospital, Bad Oldesloe, Germany), H-P. Schrenk, (Medical Clinic, Community Hospital, Bad Segeberg, Germany) and the expert and dedicated technical assistance of H. Richartz (Medical Clinic III, University of Lübeck, Germany).

\section{REFERENCES}

1 Andrews J, Nadjm B, Gant V, Shetty N. Communityacquired pneumonia. Curr Opin Pulm Med 2003; 9: 175-180.

2 Jackson ML, Neuzil KM, Thompson WW, et al. The burden of community-acquired pneumonia in seniors: results of a population-based study. Clin Infect Dis 2004; 39: 1642-1650.

3 Tleyjeh IM, Tlaygeh HM, Hejal R, Montori VM, Baddour LM. The impact of penicillin resistance on short-term mortality in hospitalized adults with pneumococcal pneumonia: a systematic review and meta-analysis. Clin Infect Dis 2006; 42: 788-797.

4 Mortensen EM, Coley CM, Singer DE, et al. Causes of death for patients with community-acquired pneumonia: results from the Pneumonia Patient Outcomes Research Team cohort study. Arch Intern Med 2002; 162: 1059-1064.

5 Potgieter PD, Hammond JM. The intensive care management, mortality and prognostic indicators in severe community-acquired pneumococcal pneumonia. Intensive Care Med 1996; 22: 1301-1306.

6 Fine MJ, Auble TE, Yealy DM, et al. A prediction rule to identify low-risk patients with community-acquired pneumonia. N Engl J Med 1997; 336: 243-250. 
7 Lim WS, van der Eerden MM, Laing R, et al. Defining community acquired pneumonia severity on presentation to hospital: an international derivation and validation study. Thorax 2003; 58: 377-382.

8 Dremsizov T, Clermont G, Kellum JA, Kalassian KG, Fine MJ, Angus DC. Severe sepsis in community-acquired pneumonia: when does it happen, and do systemic inflammatory response syndrome criteria help predict course? Chest 2006; 129: 968-978.

9 Bone RC, Grodzin CJ, Balk RA. Sepsis: a new hypothesis for pathogenesis of the disease process. Chest 1997; 112: 235-243.

10 Meehan TP, Fine MJ, Krumholz HM, et al. Quality of care, process, and outcomes in elderly patients with pneumonia. JAMA 1997; 278: 2080-2084.

11 Marrie TJ, Wu L. Factors influencing in-hospital mortality in community-acquired pneumonia: a prospective study of patients not initially admitted to the ICU. Chest 2005; 127 : 1260-1270.

12 Schaaf BM, Boehmke F, Esnaashari H, et al. Pneumococcal septic shock is associated to interleukin-10-1082 gene promoter polymorphism. Am J Respir Crit Care Med 2003; 168: 476-480.

13 Schaaf B, Rupp J, Müller-Steinhardt M, et al. The interleukin6-174 promoter polymorphism is associated with extrapulmonary bacterial dissemination in Streptococcus pneumoniae infection. Cytokine 2005; 31: 324-328.

14 National Committee for Clinical Laboratory Standards (NCCLS). Performance standards for antimicrobial susceptibility testing-14th informational supplement, approved standard M 100-S14. Wayne County, NCCLS, 2004.

15 Reinert RR, Reinert S, van der Linden M, Cil MY, AlLahham A, Appelbaum P. Antimicrobial susceptibility of
Streptococcus pneumoniae in eight European countries from 2001 to 2003. Antimicrob Agents Chemother 2005; 49: 2903-2913.

16 Brauers J, Bagel S, Kresken M. Aktuelle resistenzsituation bei bakteriellen erregern von ambulant erworbenen atemwegsinfektionen. [Resistance of bacterial pathogens in community-acquired respiratory infections.] Chemother $J$ 2005; 14: 45-53.

17 Ewig S, de Roux A, Bauer T, et al. Validation of predictive rules and indices of severity for community acquired pneumonia. Thorax 2004; 59: 421-427.

18 Reinert RR, Haupts S, van der Linden M, et al. Invasive pneumococcal disease in adults in North-Rhine Westphalia, Germany, 2001-2003. Clin Microbiol Infect 2005; 11: 985-991.

19 Bauer TT, Ewig S, Marre R, Suttorp N, Welte T, The CAPNETZ Study Group, CRB-65 predicts death from community-acquired pneumonia. J Intern Med 2006; 260: 93-101.

20 Spindler C, Ortqvist A. Prognostic score systems and community-acquired bacteraemic pneumococcal pneumonia. Eur Respir J 2006; 28: 816-823.

21 Yoshimoto A, Nakamura H, Fujimura M, Nakao S. Severe community-acquired pneumonia in an intensive care unit: risk factors for mortality. Intern Med 2005; 44: 710-716.

22 Robert Koch Institut. Empfehlung der ständigen Impfkommission (STIKO). [Guideline of the National Vaccination Committee (STIKO).] Epi Bull 2006; 30: 235-254.

$23 \mathrm{Yu} \mathrm{VL}$, Chiou CC, Feldman C, et al. An international prospective study of pneumococcal bacteremia: correlation with in vitro resistance, antibiotics administered, and clinical outcome. Clin Infect Dis 2003; 37: 230-237.

24 Ruiz M, Ewig S, Torres A, et al. Severe communityacquired pneumonia. Risk factors and follow-up epidemiology. Am J Respir Crit Care Med 1999; 160: 923-929. 